\title{
INFLUÊNCIA DA UTILIZAÇÃO DA ÁGUA DE IMERSÃO DE PALHA DE BANANEIRA SOBRE A PRODUÇÃO DE LACASE POR PLEUROTUS SAJOR-CAJU
}

\author{
M. P. de MELO ${ }^{1}$, J. R. RAMPINELLI ${ }^{1,2}$, R. M. M. GERN ${ }^{1}$, E. WISBECK ${ }^{1}$, M. L. L. \\ SILVEIRA $^{1}$, A. FURIGO JR ${ }^{2}$, M. BONATTI-CHAVES ${ }^{1}$, S. A. FURLAN ${ }^{1}$ \\ ${ }^{1}$ Universidade da Região de Joinville, Departamento de Engenharia Química \\ ${ }^{2}$ Universidade Federal de Santa Catarina, Departamento de Engenharia Química e de Engenharia \\ de Alimentos \\ E-mail para contato: mbonatti@univille.br
}

\begin{abstract}
RESUMO - Fungos do gênero Pleurotus têm demonstrado ser bons produtores de enzimas oxidativas com diversas aplicações industriais, assim sendo estudos sobre a composição de meios de cultivo que maximizem a produção destas enzimas tornaram-se alvo de muitas pesquisas. Este trabalho teve como objetivo avaliar produção de lacase por Pleurotus sajor-caju nos meios de cultivo (a) solução Manachini suplementada com $\mathrm{CuSO}_{4} 150 \mu \mathrm{M}$ e glicose $20 \mathrm{~g} / \mathrm{L}$ e (b) solução (a) tendo seus sais dissolvidos em água de imersão (resíduo oriundo da umidificação do substrato no processo de cultivo de cogumelos). Os experimentos foram realizados em biorreator de mistura completa (4L), temperatura $30^{\circ} \mathrm{C}, \mathrm{K}_{\mathrm{L}}$ a e $\mathrm{pH}$ iniciais $15 \mathrm{~h}^{-1}$ e 6,0, respectivamente. A utilização da água de imersão mostrou-se favorável para a produção de lacase por Pleurotus sajor-caju. Os meios de cultivo (a) e (b) apresentaram atividades máximas e produtividades em lacase de 222,1 e 3.132,7 U/L, respectivamente, e 1,98 e 17,1 U/L.h, respectivamente.
\end{abstract}

\section{INTRODUÇÃO}

O cultivo de fungos do gênero Pleurotus pode ser realizado em meio sólido e em meio líquido. Enzimas são produzidas e excretadas pelo fungo quando este é cultivado tanto em meio sólido quanto em meio líquido. No entanto, o cultivo em meio líquido apresenta algumas vantagens em relação ao cultivo em meio sólido, como menor área para o cultivo, maior controle de parâmetros como $\mathrm{pH}$, temperatura, etc., facilidade de extração dos produtos excretados, etc. A composição do meio de cultivo, tanto no cultivo sólido como no cultivo líquido, vem sendo investigada por vários autores com o objetivo de maximizar a produção de enzimas por fungos e diminuir custos de produção (Elisashvili et al., 2008; Gregori et al., 2008; Libardi-Júnior et al, 2011).

Segundo Gregori et al. (2008), o tipo de resíduo agroindustrial, bem como a forma de cultivo (meio sólido ou líquido), influenciam diretamente na produção de enzimas, bem como o tipo de enzima produzida. Elisashvili et al. (2008) realizaram o cultivo de Pleurotus dryinus IBB $903 \mathrm{em}$ 


\section{9 a 22 de outubro de 2014 \\ Florianópolis/SC}

meio de cultivo líquido e sólido. Estes autores observaram maior produtividade em carboximetilcelulase e xilanase em meio de cultivo líquido (152 e $168 \mathrm{U} / g$.dia, respectivamente) que em meio de cultivo sólido ( 28 e $54 \mathrm{U} / g$.dia, respectivamente). Contudo, o meio de cultivo sólido favoreceu a produção de manganês peroxidase, que em meio de cultivo líquido teve sua atividade inibida.

Libardi-Júnior et al. (2011), estudaram a produção de enzimas por Pleurotus sajor-caju em dois diferentes meios de cultivo sólido. O primeiro formulado com palha de folhas de bananeira suplementado com farelo de arroz e o segundo com palha de folhas de bananeira e cascas de banana, na proporção 2:1, também suplementado com farelo de arroz. Os autores observaram que a adição de cascas de banana ao meio de cultivo aumentou a atividade das enzimas lacase $(456,8 \mathrm{U} / \mathrm{L})$, manganês peroxidase (154,1 U/L) e xilanase (298,6 U/L) em 4,7, 11,5 e 1,4 vezes, respectivamente. Os mesmos autores estudaram a produção de lacase por Pleurotus ostreatus em meio líquido. Estes autores avaliaram três diferentes composições de meio de cultivo: (a) água destilada suplementada com $150 \mu \mathrm{M}$ de $\mathrm{CuSO}_{4}$ e $40 \mathrm{~g} / \mathrm{L}$ de pó de cascas de banana, (b) meio de cultivo Kirk suplementado com $150 \mu \mathrm{M}$ de $\mathrm{CuSO}_{4}$ e $40 \mathrm{~g} / \mathrm{L}$ de pó de cascas de banana e (c) água de imersão de palha de folhas de bananeira suplementada com $150 \mu \mathrm{M}$ de $\mathrm{CuSO}_{4}$ e $40 \mathrm{~g} / \mathrm{L}$ de pó de cascas de banana. O meio de cultivo contendo água de imersão de palha de folhas de bananeira em sua composição, ou seja, o meio de cultivo (c), foi o que propiciou a maior atividade de lacase, igual a 3.658,2 U/L, seguido dos meios de cultivo (b) e (a), com atividades de lacase iguais a 1.575,0 e 372,5 U/L, respectivamente. Observase influência positiva deste tipo de resíduo, água de imersão de palha de folhas de bananeira, sobre a produção de enzimas por Pleurotus. Quando compara-se as atividades de lacase obtidas por Pleurotus sajor-caju, cultivado em meio sólido, com aquelas obtidas por Pleurotus ostreatus, cultivado em meio líquido, observa-se aumento de 8 vezes na atividade de lacase quanto utiliza-se meio de cultivo líquido.

Assim sendo, este trabalho teve como objetivo estudar a produção de lacase por Pleurotus sajor-caju em meios de cultivo: (a) solução Manachini suplementada com $\mathrm{CuSO}_{4} 150 \mu \mathrm{M}$ e $20 \mathrm{~g} / \mathrm{L}$ de glicose e (b) solução (a) tendo seus sais dissolvidos em água de imersão ao invés de água destilada, suplementada também com $\mathrm{CuSO}_{4} 150 \mu \mathrm{M}$ e $20 \mathrm{~g} / \mathrm{L}$ de glicose. E, desta forma, avaliar a influencia deste resíduo (água de imersão) sobre a produção da enzima lacase por Pleurotus sajor-caju.

\section{MATERIAL E MÉTODOS}

\subsection{Micro-organismo e manutenção}

Foi utilizada a espécie Pleurotus sajor-caju, obtida da Coleção de Culturas de Basidiomicetos da Universidade de São Paulo, sob o código CCB 019, mantida em meio trigo-dextrose-ágar (TDA) (Furlan et al., 1997), sob refrigeração, com repiques realizados a cada três meses. 


\subsection{Preparo do inóculo}

Foram utilizados frascos Duran de 2,0 L com duas saídas, contendo $400 \mathrm{~mL}$ de solução Manachini $\left(2 \mathrm{~g} / \mathrm{L}\right.$ de $\mathrm{KH}_{2} \mathrm{PO}_{4}, 1 \mathrm{~g} / \mathrm{L}$ de $\left(\mathrm{NH}_{4}\right)_{2} \mathrm{SO}_{4}, 0,1 \mathrm{~g} / \mathrm{L}$ de $\mathrm{MgSO}_{4} .7 \mathrm{H}_{2} \mathrm{O}, 0,9 \mathrm{~g} / \mathrm{L}$ de $\mathrm{Na}_{2} \mathrm{HPO}_{4} \cdot 2 \mathrm{H}_{2} \mathrm{O}$ e $1 \mathrm{~g} / \mathrm{L}$ de extrato de levedura) suplementada com $20 \mathrm{~g} / \mathrm{L}$ de glicose. Os meios de cultivo foram inoculados com micélio de 7 dias, contido em uma placa de Petri (Furlan et al., 2008), e incubados a $30^{\circ} \mathrm{C}$ por 6 dias sob agitação de $110 \mathrm{~min}^{-1}$.

\subsection{Cultivo em biorreator}

Foram utilizados dois meios de cultivo. Inicialmente, utilizou-se solução Manachini suplementada com $20 \mathrm{~g} / \mathrm{L}$ de glicose e $150 \mu \mathrm{M}$ de $\mathrm{CuSO}_{4}$, sendo todos os sais dissolvidos em água destilada. Em seguida, realizou-se o cultivo utilizando solução Manachini, também suplementada com $20 \mathrm{~g} / \mathrm{L}$ de glicose e $150 \mu \mathrm{M}$ de $\mathrm{CuSO}_{4}$, porém sendo os sais dissolvidos em água de imersão ao invés de água destilada.

Todos os experimentos foram conduzidos em regime descontínuo, sem controle do $\mathrm{pH}$ ( $\mathrm{pH}$ inicial ajustado em 6,0), em biorreator de mistura completa Sartorius Stedim, modelo Biostat® B Plus, com dorna de vidro de capacidade de trabalho de 4 L. A fração de inóculo foi de $10 \%$, ou seja, $400 \mathrm{~mL}$. A temperatura foi fixada em $30^{\circ} \mathrm{C}$, o fluxo de ar em 0,4 vvm (volume de ar por volume de meio por minuto) e a frequência de agitação em $350 \mathrm{~min}^{-1}$, gerando $\mathrm{kLa}$ inicial (coeficiente volumétrico de transferência de oxigênio) de $15 \mathrm{~h}^{-1}$. Os experimentos foram realizados em duplicata.

\subsection{Métodos analíticos}

\subsubsection{Concentração celular}

A concentração celular foi determinada através de método gravimétrico. Uma amostra de 20 $\mathrm{mL}$ foi retirada periodicamente, filtrada em papel Whatman $\mathrm{n}^{\circ} 1$, lavada com água destilada, transferida para cadinhos previamente pesados e secos por 48 horas a $90^{\circ} \mathrm{C}$. A massa obtida após a secagem da biomassa em estufa por 48 horas a $60^{\circ} \mathrm{C}$ foi dividida pelo volume da amostra e o resultado obtido expresso em $\mathrm{g} / \mathrm{L}$.

\subsubsection{Concentração de glicose}

A concentração de glicose foi medida pelo método Glicose-E (ANALISA, Gold Analisa Diagnóstica Ltda.). Neste método, a glicose é oxidada pela enzima glicose-oxidase (GOD) a ácido glucônico e peróxido de hidrogênio (a). Em presença de peroxidase (POD), o peróxido de hidrogênio 
produz a copulação oxidativa do fenol com a 4-aminofenazona (4-AF), dando lugar à formação de um cromógeno vermelho cereja (b), cuja intensidade da cor é proporcional à concentração de glicose presente na solução em análise (Trinder, 1969). As leituras de absorbância foram feitas em espectrofotômetro (modelo SP 2000UV, BEL PHOTONICS) a $505 \mathrm{~nm}$. Com base nas leituras obtidas com os padrões (concentração de 0,1 a 1,0 g/L), foi definida uma equação, por regressão linear, através da qual foram calculadas as concentrações de glicose nas amostras.

\subsubsection{Atividade de lacase}

A atividade da enzima lacase foi determinada pelo monitoramento do aumento da absorbância $(420 \mathrm{~nm})$, produzida pela oxidação do composto ABTS (2,2-azino-bis-[3-ethyltiazoline-6-sulfonate]), utilizado como substrato, em um volume de $0,8 \mathrm{~mL}$, ao qual acrescentou-se $0,1 \mathrm{~mL}$ de solução tampão acetato de sódio 0,1M (pH 5,0) e 0,1 mL do caldo enzimático (Buswell et al., 1996). Uma unidade de atividade de enzima foi definida como a quantidade de enzima necessária para oxidar 1 $\mu \mathrm{mol}$ do subtrato ABTS por minuto, utilizando o coeficiente de extinção molar de $36000 \mathrm{M}^{-1} . \mathrm{cm}^{-1}$.

\subsubsection{Metodologia utilizada para os cálculos cinéticos}

Utilizou-se para o cálculo das produtividades global e máxima (U/L.h) as fórmulas $\mathrm{Q}_{\mathrm{Lac}}=\left(\mathrm{Lac}_{\mathrm{Max}}-\mathrm{Lac}_{0}\right) / \mathrm{t}$, em que t é o tempo onde a concentração de lacase é máxima, definido como tempo de processo, e $\mathrm{Q}_{\text {LacMáx }}=\left(\operatorname{Lac}_{\text {ProdMáx }}-\mathrm{Lac}_{0}\right) / \mathrm{t}_{\text {ProdMáx }}$, em que $\mathrm{Lac}_{\text {ProdMáx }}$ é a concentração de lacase no tempo em que a produtividade em lacase é máxima ( tProdMáx $_{\text {) }}$.

\subsubsection{Construção das curvas cinéticas}

As curvas cinéticas de crescimento celular, consumo de glicose, atividade de lacase e pH foram traçadas utilizando-se os pontos experimentais de cada repetição (experimentos realizados em duplicata). O software para tratamento de dados experimentais de cultivo microbiano (EMERSON), desenvolvido no Instituto de Pesquisas Tecnológicas de São Paulo (IPT) por Wagner Bruna e Manuel F. Barral foi utilizado para a obtenção das curvas "fantasmas" de crescimento celular e consumo de glicose. O programa Origin 8.0 PRO® foi utilizado para desenhar os gráficos contendo as curvas "fantasmas" juntamente com os pontos experimentais de cada experimento.

\section{RESULTADOS E DISCUSSÃO}




\subsection{Produção de lacase em meio Manachini utilizando água destilada e água de imersão na composição do meio de cultivo}

A Figura1 mostra as variações das concentrações de glicose e biomassa micelial, assim como da atividade de lacase e do valor de $\mathrm{pH}$, com o tempo de cultivo de Pleurotus sajor-caju em processo descontínuo simples, utilizando solução Manachini, suplementada com $20 \mathrm{~g} / \mathrm{L}$ de glicose e $150 \mu \mathrm{M}$ de $\mathrm{CuSO}_{4}$.

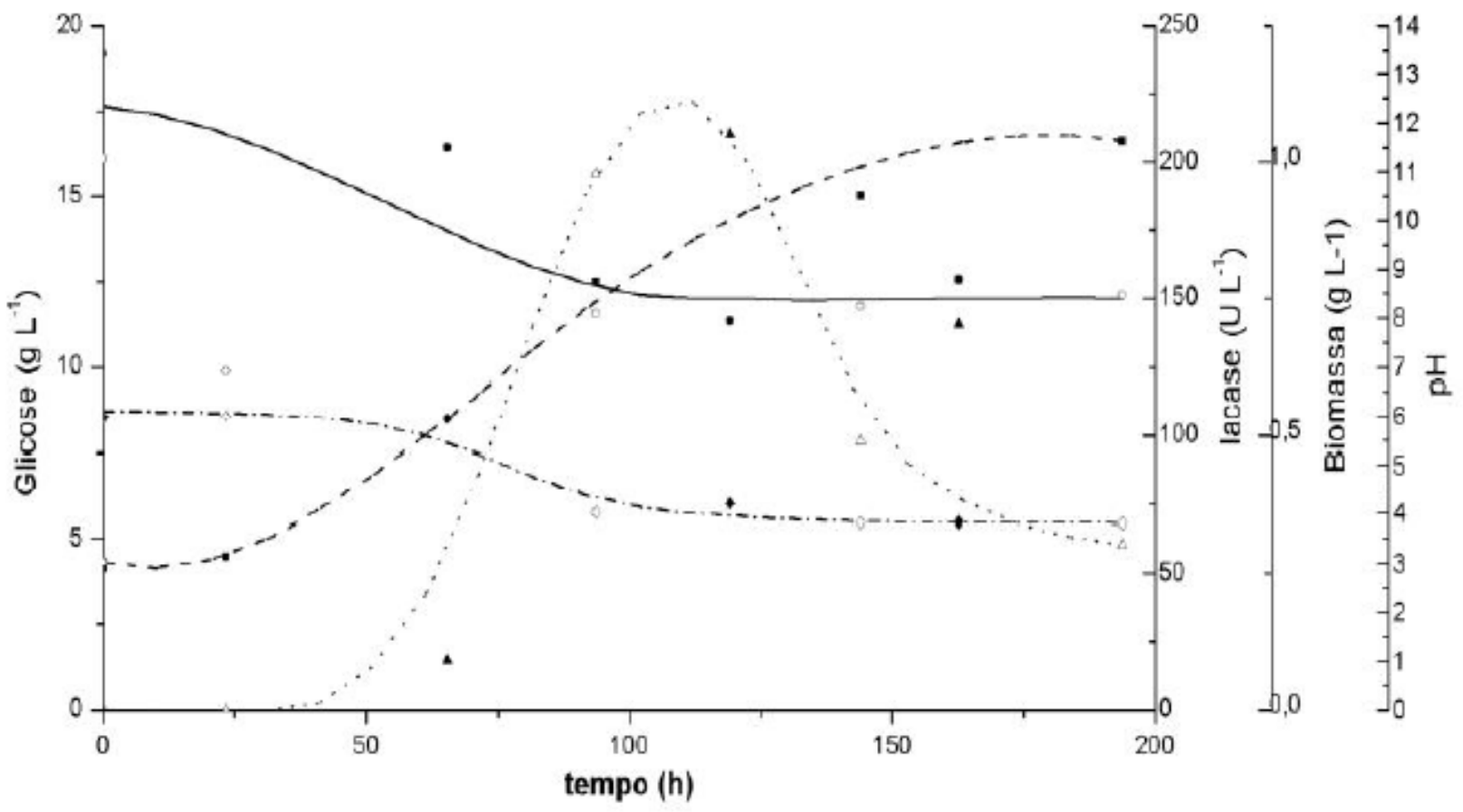

Figura 1 - Variações das concentrações de glicose (linha contínua), biomassa (linha tracejada), atividade de lacase (linha pontilhada) e pH (linha tracejada e pontilhada) em função do tempo (h) durante o cultivo de Pleurotus sajor-caju, em processo descontínuo simples, utilizando solução Manachini em água destilada. Os símbolos aberto e fechado representam as duplicatas do

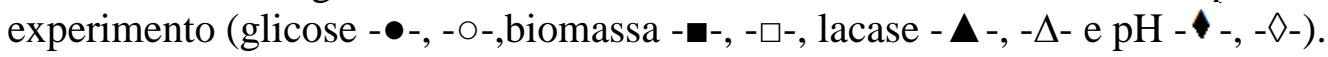

Observa-se por meio da Figura 1 a maior atividade de lacase (222,1 U/L) em torno de $112 \mathrm{~h}$ de cultivo, definido como tempo de processo. A partir deste tempo, ocorre estabilização do $\mathrm{pH}$ em torno de 3,8 e ausência do consumo de glicose, sendo a concentração de glicose residual de aproximadamente $12 \mathrm{~g} / \mathrm{L}$. Após aproximadamente $170 \mathrm{~h}$ de cultivo, nenhum dos parâmetros avaliados 
sofreu alteração com o tempo. Em relação a biomassa micelial, até $150 \mathrm{~h}$ observa-se aumento da sua concentração (de 0,27 para 1,04 g/L), porém comparando-se este valor com dados de literatura (Mikiashvili et al., 2006; Correa, 2011) este apresenta-se inferior, evidenciando o desfavorecimento deste tipo de meio de cultivo para produção de biomassa. Contudo, a atividade de lacase encontrada foi similar a encontrada em literatura para o mesmo gênero de fungo cultivado em meio líquido.

A Figura 2 mostra as variações das concentrações de glicose e biomassa micelial, assim como da atividade de lacase e do valor de $\mathrm{pH}$, com o tempo de cultivo de Pleurotus sajor-caju em processo descontínuo simples, em solução Manachini, suplementada com $20 \mathrm{~g} / \mathrm{L}$ de glicose e $150 \mu \mathrm{M}$ de $\mathrm{CuSO}_{4}$, porém sendo todos os sais dissolvidos em água de imersão ao invés de água destilada.

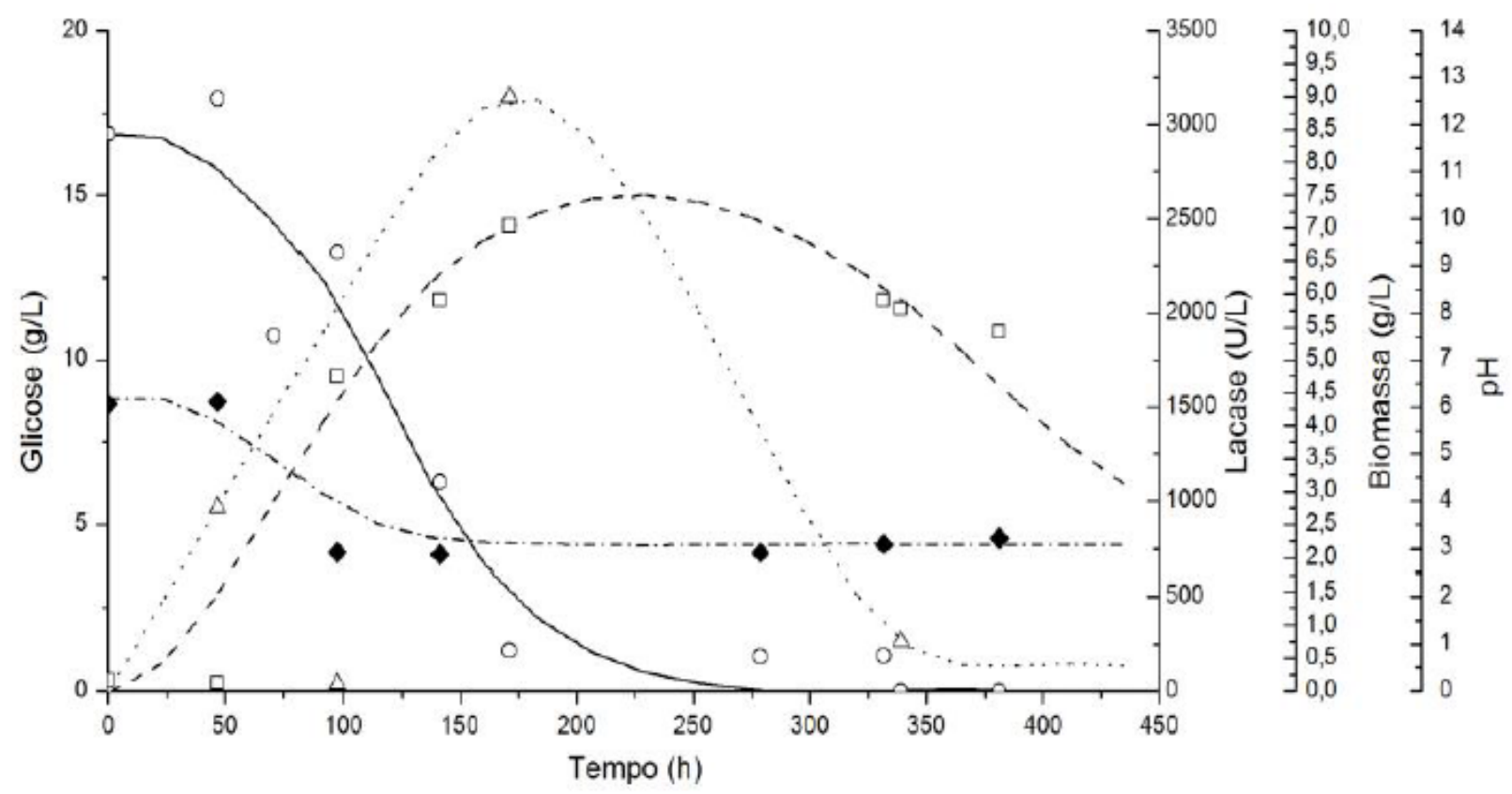

Figura 2 - Variações das concentrações de glicose (linha contínua), biomassa (linha tracejada), atividade de lacase (linha pontilhada) e pH (linha tracejada e pontilhada) em função do tempo (h) durante o cultivo de Pleurotus sajor-caju, em processo descontínuo simples, utilizando solução Manachini em água de imersão. Os símbolos aberto e fechado representam as duplicatas do

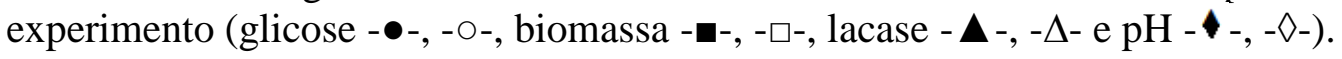

Observa-se por meio da Figura 2 maior atividade de lacase (3.132,7 U/L) em 182,8 h de cultivo definido como tempo de processo. Neste tempo a concentração de biomassa é de 7,2 g/L. A partir deste tempo, ocorre estabilização do $\mathrm{pH}$ em torno de 3,0, a concentração de glicose aproximase de zero (aproximadamente $2 \mathrm{~g} / \mathrm{L}$ ) e observa-se diminuição do crescimento, seguido de lise celular. 


\section{9 a 22 de outubro de 2014 \\ Florianópolis/SC}

Comparando-se os valores de atividade de lacase e concentração celular nos experimentos com e sem o uso de água de imersão, observa-se aumento de ambos os parâmetros. Observa-se aumento de aproximadamente 14 e 7 vezes na atividade de lacase e concentração de biomassa, respectivamente, quando utiliza-se água de imersão na composição do meio de cultivo. Os valores encontrados de produtividades global e máxima também foram maiores quando utilizou-se água de imersão na composição dos meios de cultivo. As produtividades global e máxima para os cultivos realizados em solução Manachini suplementada com $20 \mathrm{~g} / \mathrm{L}$ de glicose e $150 \mu \mathrm{M}$ de $\mathrm{CuSO}_{4}$, sendo os sais dissolvidos em água de imersão foram 17,1 e 20,9 U/L.h, respectivamente. Enquanto, as produtividades global e máxima para os cultivos sem o uso de água de imersão foram 1,98 e 10,5 U/L.h.

Os valores de atividade de lacase obtidos neste trabalho, utilizando água de imersão na composição do meio de cultivo, foram similares aos obtidos por Libardi-Júnior et al. (2011), que avaliaram três diferentes composições de meio de cultivo: (a) água destilada suplementada com 150 $\mu \mathrm{M}$ de $\mathrm{CuSO}_{4}$ e $40 \mathrm{~g} / \mathrm{L}$ de pó de cascas de banana, (b) meio de cultivo Kirk suplementado com 150 $\mu \mathrm{M}$ de $\mathrm{CuSO}_{4}$ e $40 \mathrm{~g} / \mathrm{L}$ de pó de cascas de banana e (c) água de imersão de palha de folhas de bananeira suplementada com $150 \mu \mathrm{M}$ de $\mathrm{CuSO}_{4}$ e $40 \mathrm{~g} / \mathrm{L}$ de pó de cascas de banana. $\mathrm{O}$ meio de cultivo contendo água de imersão de palha de folhas de bananeira em sua composição, ou seja, o meio de cultivo (c) foi o que propiciou a maior atividade de lacase, igual a 3.658,2 U/L, seguido dos meios de cultivo (b) e (a), com atividades de lacase iguais a 1.575,0 e 372,5 U/L, respectivamente. Estes autores observaram influência positiva do resíduo água de imersão de palha de folhas de bananeira sobre a produção de enzimas por Pleurotus ostreatus. Os mesmos autores obtiveram atividade de lacase por Pleurotus ostreatus variando de 3,5 a 9,5 U/L quando utilizaram meio de cultivo Kirk e diferentes composições como adição de pedaços de madeira e/ou pedaços de filtro de papel Whatmann n. 1, etc. Estes valores ficaram muito abaixo dos obtidos nestes trabalho.

Correa (2011) obtiveram valores de atividade de lacase superiores aos obtidos neste trabalho e também observaram efeito positivo do resíduo água de imersão de palha de folhas de bananeira sobre a produção de enzimas por Pleurotus. Estes autores estudaram a utilização de resíduos da bananicultura, palha de folhas de bananeira e cascas de banana, para a produção de lacase, celulase, carboximetilcelulase e xilanase por Pleurotus ostreatus e Pleurotus sajor-caju em meio líquido. Três formulações foram avaliadas: (a) água de imersão de palha de bananeira + cascas de banana (2:1) suplementada com $40 \mathrm{~g} / \mathrm{L}$ de palha de bananeira triturada e $150 \mu \mathrm{M}$ de $\mathrm{CuSO}_{4}$; (b) formulação (a) suplementada com $10 \mathrm{~g} / \mathrm{L}$ de glicose e (c) meio de cultivo Kirk suplementado com $40 \mathrm{~g} / \mathrm{L}$ de palha de bananeira triturada e $150 \mu \mathrm{M} \mathrm{CuSO}_{4}$. Observou-se atividade de lacase em todos os meios avaliados para ambas as espécies, sendo a maior concentração (4.210,76 \306 U/L) obtida com o meio (b) e a espécie Pleurotus sajor-caju. As demais enzimas não apresentaram atividade enzimática.

\section{CONCLUSÃO}

Observa-se de acordo com os resultados obtidos aumento de aproximadamente 14 vezes na produção de lacase por Pleurotus sajor-caju quando utilizou-se para dissolução dos sais água de 
imersão (um resíduo agro-industrial abundante na região nordeste da Santa Catarina e utilizado para a produção de cogumelos) ao invés de água destilada. As produtividades global e máxima também foram aumentadas, em 8,5 e 10,5 vezes, respectivamente.

\section{REFERÊNCIAS}

BUSWELL, J.A., CAI, Y., CHANG, S. (1996). Effect of nutrient nitrogen and manganese on manganese peroxidase and lactase production by Lentinula (Lentinus) edodes. FEMS Microbiology Letters, v.128, p 81-88.

CORREA, M. Capacidade de descoloração de corantes têxteis por Pleurotus ostreatus. Trabalho de conclusão de curso (Graduação em Engenharia Química), Universidade da Região de Joinville, Joinville, 2011.

ELISASHVILI, V.; PENNICKX, M.; KACHLISHVILI, E.; TASIKLAURI, N.; METREVELI, E.; KHARZIANI, T.; KVESITADZE, G. Lentinus edodes and Pleurotus species lignocellulolytic enzymes activity in submerged and solid-state fermentation of lignocellulosic wastes of diferent composition. Bioresource Technology, v. 99, p. 457-462, 2008.

FURLAN, S.A.; VIRMOND, L.J.; MIERS, D.A.; BONATTI, M.; GERN, R. M. M.; JONAS, R. Mushroom strains able to grow at high temperatures and low $\mathrm{pH}$ values. World Journal of Microbiology Biotechnology, v. 13(6), p. 689-692, 1997.

FURLAN, S. A.; GERN, R. M. M.; WISBECK, B.; BONATTI, M.; SILVEIRA, M. L. L.; SILVA, H. H. Possibilities of Pleurotus applications in food, health and environmental technologies. In: KOUTINAS, A.; PANDEY, A.; LARROCHE, C. Current topics on Bioprocesses in Food Industry. Nova Delhi: Asiatech, v. 2, cap. 16, p. 197-203, 2008.

GREGORI A, VAGELJ M S, PAHOR B, BEROVIC M, POHLEVEN F, The use of spent brewery grains for Pleurotus ostreatus cultivation and enzyme production, New Biotechnology, 25(2/3), 157-161, 2008.

LIBARDI JUNIOR, L.; CORREA, M.; BONATTI-CHAVES, M.; GERN, R. M. M.; WISBECK, E.; SCHLOSSER, D.; FURLAN, S. A. Production and Applications of Pleurotus laccase. In: Advances in Bioprocess in Food Industry. Vol. IV. Nova Delhi: Asiatech, p. 36-61, 2011.

MIKIASHVILI, N.; WASSER, S.P.; NEVO, E. and ELISASHVILI, V. Effects of carbon and nitrogen sources on Pleureotus ostreaus ligninolytic enzyme activity. World Journal of Microbiology and Biotechnology, vol. 22, no. 9, p. 999-1002, 2006.

TRINDER, R. Instruções para a determinação enzimática de glicose pelo método Glicose-E. Ann. Clin. Biochem. In: CELM - Cia Equipadora de Laboratórios Modernos, São Paulo, 1969. 